\title{
Climate-induced shifts in an experimental phytoplankton community: a mechanistic approach
}

\author{
Lisette N. De Senerpont Domis - Wolf M. Mooij • \\ Jef Huisman
}

(C) Springer Science+Business Media B.V. 2007

\begin{abstract}
Climate change is likely to have farreaching effects on biotic interactions in aquatic ecosystems. We investigated the effect of different spring warming scenarios on the succession of three algal groups (cyanobacteria, diatoms and green algae) in 10-1 microcosms. We fitted these microcosm data to a simple mechanistic model to estimate the effect of different climate warming scenarios on the population dynamics of these algal functional groups. Experimental and model results indicate that the different algal functional groups respond differently to climate warming under phosphorus-limited conditions. Whereas the successional sequence, from diatoms to green algae to cyanobacteria, was not affected by the different climate warming scenarios, cyanobacteria showed a stronger response to the different
\end{abstract}

Guest editors: R. D. Gulati, E. Lammens, N. De Pauw \& E. Van Donk

Shallow lakes in a changing world

L. N. De Senerpont Domis $(\bowtie) \cdot$ W. M. Mooij Netherlands Institute of Ecology (NIOO-KNAW), Centre for Limnology, Rijksstraatweg 6, 3631 AC

Nieuwersluis, The Netherlands

e-mail: 1.desenerpontdomis@nioo.knaw.nl

J. Huisman

Aquatic Microbiology, Institute for Biodiversity and Ecosystem Dynamics, University of Amsterdam, Nieuwe Achtergracht 127, 1018 WS Amsterdam, The Netherlands climate warming scenarios than diatoms or green algae. Both the growth rates and peak abundances of cyanobacteria were significantly higher in the average and warm spring scenarios than in the cold spring scenario. Our findings illustrate that integration of models and microcosm experiments are a useful approach in predicting the impacts of rising temperatures on the dynamics of phytoplankton communities.

Keywords Community dynamics - Climate change - Freshwater - Cyanobacteria - Green algae $\cdot$ Diatoms $\cdot$ Mechanistic model $\cdot$ Spring warming

\section{Introduction}

Over the past century the global temperature has increased on average by $\sim 0.6$ degrees Celsius (Houghton et al., 2001). Climate change models predict a further increase in temperate of $1.4-5.8^{\circ} \mathrm{C}$ by the year 2100 , depending on emission scenarios (Houghton et al., 2001). This projected climate change is likely to have farreaching effects on biotic interactions across different ecosystems, including range boundary shifts, physiological and genetic adaptation, shifts in phenology and shifts in community composition (Walther et al., 2002; Parmesan \& Yohe, 2003; Mooij et al., 2005). 
According to regional models predicting changes in climate in the Netherlands, both temperature and precipitation are expected to increase, resulting in mild and wet winters, warmer springs and a higher incidence of extreme weather events (Kors et al., 2000). The strongest temperature increase is expected during late winter and early spring (Van Vliet et al., 2002; Van Oldenborgh \& Van Ulden, 2003). During late winter and early spring, most lakes in temperate regions start to develop a characteristic seasonal succession of phytoplankton groups (Sommer et al., 1986). An initial spring bloom of small algae (e.g. centric diatoms and cryptophyceae) is triggered by ample nutrient and light availability towards the end of winter. In shallow lakes, this initial bloom of small algae is soon replaced by large pennate diatoms, e.g. Asterionella, and in summer by green algae and cyanobacteria (Sommer et al., 1986; Reynolds, 1997).

Time series analysis of lakes in north Western Europe showed a strong correlation between the timing of algal spring bloom formation and proxies of climate change (Müller-Navarra et al., 1997; Adrian et al., 1999; Weyhenmeyer et al., 1999; Gerten \& Adrian, 2000). In the past decades, the spring bloom started earlier after warmer winters. Such changes in algal phenology may result in a decoupling of trophic relationships, when the advancement of the spring bloom is not followed by similar changes in the timing of key herbivores like Daphnia (Winder \& Schindler, 2004a, b). Climate change may also cause quantitative changes in phytoplankton community dynamics, shown as changes in phytoplankton species composition or changes in the seasonal succession of phytoplankton groups. In among-lake comparisons of phytoplankton community composition, both Adrian et al. (1995) and Weyhenmeyer (2001) report that rising temperatures are accompanied by a higher biomass of cyanobacteria.

Climate warming may favour cyanobacteria over diatoms and to lesser extent green algae, both directly and indirectly. As a major direct effect, Reynolds (1997) showed that with increasing temperature, the maximum growth rate of the cyanobacteria Microcystis aeruginosa increased almost twice as much as that of the green alga
Scenedesmus quadriqauda and almost five times as much as that of the diatom Asterionella formosa. Coles and Jones (2000) found similar differences in temperature-dependent growth rates between three cyanobacteria (Microcystis aeruginosa, Merismopedia tenuissima and Oscillatoria sp.) and the diatom Aulacoseira granulata var. angustissima. Surprisingly, however, Moss et al. (2003) did not report an increase in the abundance of cyanobacteria with temperature in experimental microcosms. Rising temperatures will also affect phytoplankton communities in indirect ways. For instance, changes in the heat budget of lakes induce seasonal changes in stratification and turbulent mixing. Reduced turbulent mixing and enhanced stratification facilitate the development of surface blooms in eutrophic lakes, thereby shifting the species composition of phytoplankton communities in favour of buoyant cyanobacteria (Harris \& Baxter, 1996; Huisman et al., 2004). Furthermore, climate warming may enhance the eutrophication of freshwater ecosystems (Mckee et al., 2003; Van de Bund et al., 2004; Christoffersen et al., 2006), which may also facilitate the potential of cyanobacteria to dominate the phytoplankton community (Elliott et al., 2006).

Experimental research mimicking climate change scenarios in natural lakes is a useful tool to predict the impact of future climate change on lake phytoplankton dynamics. Here, we investigate the effect of different spring warming scenarios on the succession of three algal groups (cyanobacteria, diatoms and green algae) in 10-1 microcosms. So far, only a few studies have reported the direct effect of rising temperature on phytoplankton community structure (Weyhenmeyer et al., 1999; Weyhenmeyer, 2001; Moss et al., 2003). Laboratory microcosms cannot mimic all aspects of climate change, e.g. hydrodynamic processes. However, microcosms do allow detailed investigation of specific mechanisms under controlled conditions. Our 10-1 microcosms enable the growth of natural phytoplankton assemblages under controlled laboratory conditions, thus providing an intermediate step of realism and control between artificial plankton communities (Beisner et al., 1996, 1997), large-scale outdoor mesocosms (Moss et al., 2003; 
Strecker et al., 2004; Christoffersen et al., 2006) and correlational time series analysis. We fit these microcosm data to a simple mechanistic model to estimate the effects of warming on algal growth rates and mortality rates. This allows us to examine how different spring warming scenarios may affect the population dynamics of the three algal groups. Our overall hypothesis is that, in accordance with the results of time series analysis (Gerten \& Adrian, 2000; Weyhenmeyer, 2001; Weyhenmeyer et al., 2002), increased warming will affect the succession of the different algal groups. In particular, we expect that, given the higher temperature optimum of cyanobacteria (Reynolds, 1997; Coles \& Jones, 2000), increased warming will result in higher cyanobacterial abundance.

\section{Material and methods}

\section{Experimental set-up}

Plankton inoculum was obtained from shallow eutrophic Lake Tjeukemeer; in the northern part of The Netherlands $\left(52^{\circ} 5 \mathrm{~N}, 5^{\circ} 5 \mathrm{E}\right)$ on February, 15, 2005. The plankton inoculum was sampled at $0.5-1.0 \mathrm{~m}$ depth. Large zooplankton was removed by filtering through an $80 \mu \mathrm{m}$ mesh. Small zooplankton (e.g. rotifers and small crustaceans) was removed by gently bubbling the inoculum with nitrogen gas at $2 \mathrm{~h}$ intervals for $24 \mathrm{~h}$ (Sommer, 1985). To acclimatize the phytoplankton community to laboratory conditions and to ensure an evenly distributed phytoplankton composition of the culture vessels, the phytoplankton inoculum was first precultured in a large mesocosm for a period of 8 days at $8^{\circ} \mathrm{C}$ (Verschoor et al., 2003). After this incubation period, 12 experimental 10-1 vessels (transparent polycarbonate carboys; NALGENE, Rochester, USA) were each inoculated with 101 phytoplankton suspension.

Phytoplankton communities were cultured for 61 days, using light and temperature conditions representative for the period between Julian day 110 and 172 in The Netherlands (Mooij \& Van Tongeren, 1990). This period matches the timing of the phytoplankton spring bloom. The experi- mental vessels were treated as semi-continuous cultures. They were supplied daily with oligomesotrophic lake water (Lake Maarsseveen), filtered through a $0.45 \mu \mathrm{m}$ membrane filter (Schleicher and Schuell Microscience, Dassel, Germany). The dilution rate was $0.0395 \mathrm{~d}^{-1}$. Cultures were mixed for $15 \mathrm{~min}$ at $100 \mathrm{RPM}$ every two hours, using a magnetic stirrer. Cultures were also stirred manually prior to sampling. All experimental vessels received a constant air supply. PHILIPS TLD 30W/33 coolwhite fluorescent tubes were used as light source $\left(120 \mu \mathrm{mol}\right.$ photons $\mathrm{m}^{-2} \mathrm{~s}^{-1}$, integrated over PAR range). The day-night light cycle simulated natural spring conditions in the Netherlands, i.e. daylight was gradually increased from $14 \mathrm{~h}$ and $15 \mathrm{~min}$ at the start to $16 \mathrm{~h}$ and $55 \mathrm{~min}$ daylight at the end of the experiment.

We chose three climate scenarios, reflecting the seasonal rise in water temperature during a cold, an average, and a warm spring (Fig. 1). Temperature ranged from $9^{\circ} \mathrm{C}$ to $13^{\circ} \mathrm{C}$ in a cold spring, from $9^{\circ} \mathrm{C}$ to $19^{\circ} \mathrm{C}$ in an average spring, and from $9^{\circ} \mathrm{C}$ to $25^{\circ} \mathrm{C}$ in a warm spring. These climate scenarios fell within the bandwidth of spring warming regimes measured in Lake Tjeukemeer between Julian day 110 and 172 during the period

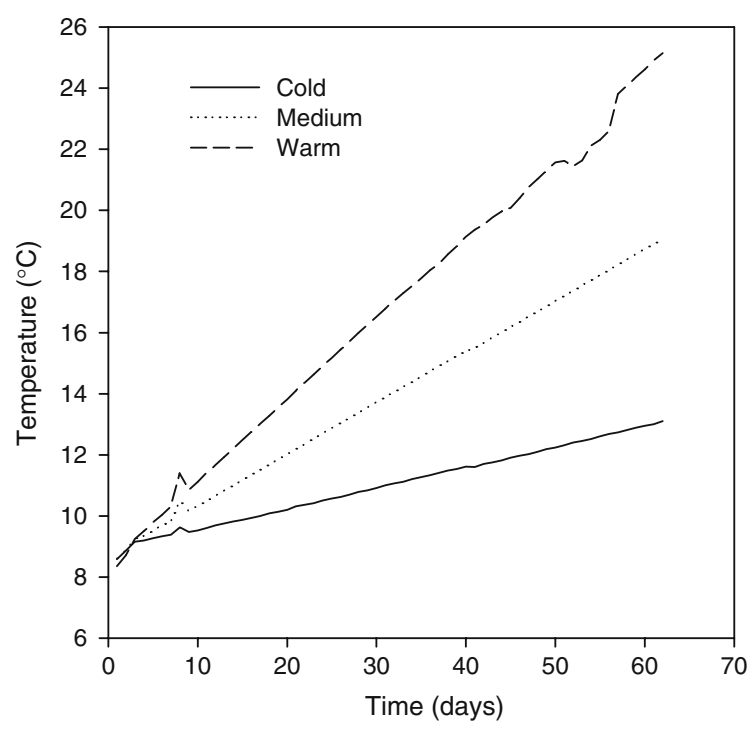

Fig. 1 Time course of temperature in the three climate scenarios simulated by the experiments. Cold $=$ cold spring scenario, Medium $=$ average spring scenario, Warm $=$ warm spring scenario 
of 1971-1987 (Mooij, 1996). The water temperature at Julian day 172 can be more than $12^{\circ} \mathrm{C}$ higher in a warm spring than in a cold spring (Fig. 1). Each climate scenario was replicated four times. The rising temperatures were automated using the FAREX SR minisystem (RKC instruments inc., Tokyo, Japan), ensuring a temperature control of $\pm 0.5^{\circ} \mathrm{C}$.

Sampling procedure and data acquisition

Throughout the experimental period, temperature was measured every minute. Phytoplankton was sampled daily, using a sampling tube with an inner diameter of $56 \mathrm{~mm}$ (De Nie et al., 1980). Immediately after sampling, the total sampling volume $(395 \mathrm{ml})$ was filtered over a $60 \mu \mathrm{m}$ mesh to separate larger phytoplankton (e.g. the diatom Asterionella formosa) from smaller phytoplankton (e.g. Scenedesmus sp.).

On a daily basis, a $10 \mathrm{ml}$ subsample was taken from the filtrate for pulse-amplitude modulated fluorometry (PHYTO-PAM, Effeltrich, Germany). Based on the relative proportion of pigments present in phytoplankton species $\mathrm{PHY}$ TO-PAM analysis estimates the relative abundances of different phytoplankton groups, i.e. cyanobacteria, green algae and diatoms (Walz, 1999).

A $50 \mathrm{ml}$ subsample was taken from the filtrate every third day for nutrient analysis, and immediately filtered through aquadest rinsed glass microfibre filters (Whatman GF/F, Maidstone, UK). The residue was used to estimate weight of the total seston fraction smaller than $60 \mu \mathrm{m}$. The filtrate was preserved at $-20^{\circ} \mathrm{C}$ for later nutrient analysis. Soluble reactive phosphorus (SRP) was determined according to Murphy and Riley (1962). Soluble reactive silicon (referred to as silicate) was measured according to Golterman et al. (1978).

Statistical analysis of experimental data

We tested whether the time course of the phytoplankton community and SRP concentration showed significant differences between treatments using an Analysis of Variance for repeated measurements (rANOVA). Variables were square-root transformed prior to analysis, if so required to meet the assumptions of rANOVA and ANOVA.

\section{Model analysis of experimental data}

To simulate phytoplankton succession under different climate scenarios we developed a competition model in which the abundances of green algae $\left(A_{\mathrm{G}}\right)$, cyanobacteria $\left(A_{\mathrm{C}}\right)$ and diatoms $\left(A_{\mathrm{D}}\right)$ depend on the concentration of one or more limiting nutrients $(N)$. Because the experiments revealed that diatoms decreased from the start, whereas green algae and cyanobacteria initially increased, we assume that there are two limiting nutrients in the system. Indeed, nutrient analysis of the culture medium showed low concentrations of silicate for the greater part of the experimental period, most probably limiting diatom growth, whereas SRP reached limiting concentrations only after experimental day 18 . Therefore, we omitted an autonomous growth term for the diatoms. Thus, our model is described by the following differential equations:

$$
\frac{\mathrm{d} N}{\mathrm{~d} t}=-c\left(r_{C} A_{C}+r_{G} A_{G}\right) \frac{N}{H_{N}+N}-D N
$$

$\frac{\mathrm{d} A_{D}}{\mathrm{~d} t}=-d_{D} A_{D}-D A_{D}$

$\frac{\mathrm{d} A_{G}}{\mathrm{~d} t}=r_{G} A_{G} \frac{N}{H_{N}+N}-D A_{G}$

$\frac{\mathrm{d} A_{C}}{\mathrm{~d} t}=r_{C} A_{C} \frac{N}{H_{N}+N}-D A_{C}$

Here, $r_{\mathrm{C}}$ and $r_{\mathrm{G}}$ are the specific growth rates of the cyanobacteria and green algae and parameter $c$ represents the nutrient content of these algal species. We assigned an extra mortality term, $d_{\mathrm{D}}$, to the diatoms, because they decreased faster than predicted on the basis of the dilution rate alone. We use the same value of the 
Table 1 Parameters and state variables of the mechanistic algal succession model

a Set a priori on basis of experimental designs

b Set a priori

c Estimated from data

\begin{tabular}{llll}
\hline Par/State variable & Value & Unit & Description \\
\hline$N$ & - & $\mu \mathrm{g} \mathrm{P} \mathrm{l}{ }^{-1}$ & Limiting nutrients \\
$A_{\mathrm{D}}$ & - & $\mu \mathrm{g} \mathrm{Chl} a \mathrm{l}^{-1}$ & Abundance of diatoms \\
$A_{\mathrm{G}}$ & - & $\mu \mathrm{g} \mathrm{Chl} a \mathrm{l}^{-1}$ & Abundance of green algae \\
$A_{\mathrm{C}}$ & - & $\mu \mathrm{g} \mathrm{Chl} a \mathrm{l}^{-1}$ & Abundance of cyanobacteria \\
$c$ & 1.77 & $\mu \mathrm{g} \mathrm{P} / \mu \mathrm{g} \mathrm{Chl} a$ & Nutrient content of algae \\
$D$ & 0.0395 & $\mathrm{~d}^{-1}$ & Dilution rate \\
$H_{\mathrm{N}}$ & 2.0 & $\mu \mathrm{g} \mathrm{P} \mathrm{l}$ & Half saturation constant $^{\mathrm{b}}$ \\
$d_{\mathrm{D}}$ & 0.0243 & $\mathrm{~d}^{-1}$ & Mortality rate of diatoms $^{\mathrm{c}}$ \\
$r_{\mathrm{G}}$ & 0.200 & $\mathrm{~d}^{-1}$ & Growth rate of green algae $^{\mathrm{c}}$ \\
$r_{\mathrm{G}}$ & 0.143 & $\mathrm{~d}^{-1}$ & Growth rate of cyanobacteria $^{\mathrm{c}}$ \\
\hline
\end{tabular}

half-saturation constant, $H_{\mathrm{N}}$, for both green algae and cyanobacteria, because the model fit did not improve significantly when these two algal groups were each assigned their own half-saturation constant. Finally, we note that all four state variables (i.e. $N, A_{\mathrm{D}}, A_{\mathrm{G}}$ and $A_{\mathrm{C}}$ ) are subjected to the same dilution rate of $D=0.0395 \mathrm{~d}^{-1}$. The model parameters and state variables are described in further detail in Table 1. Model fits were obtained by minimization of the residual sum of squares of square-root transformed observed and modelled values of the three phytoplankton groups. After fitting the model to the algal data we estimated parameter $\mathrm{c}$ by fitting the resulting nutrient dynamics to the SRP data. Applying a wide range of values for the halfsaturation constants showed that the precise value of this parameter hardly affected the fit of the model. The only difference is that low values of the half-saturation constant resulted in a sharp transition from ample nutrient availability to strong nutrient limitation (i.e. within a day), whereas high values of the half-saturation constant resulted in a more gradual transition (i.e. a couple of days).

To quantify the effect of different climate scenarios on the model parameters, we fitted the model to the time series data of the experiments. Given three climate treatments, with four replicates each, this resulted in 12 independent estimates of the growth rate of green algae $\left(r_{\mathrm{G}}\right)$, the growth rate of cyanobacteria $\left(r_{\mathrm{C}}\right)$ and the mortality rate of diatoms $\left(d_{\mathrm{D}}\right)$. Using one-way ANOVA, these parameter estimates were tested for climate treatment effects. Pairwise comparisons were carried out, using Tukey HSD. Prior to analyses, data were checked for normality and homogeneity of variances. All statistical analyses were performed using the software package STATISTICA version 7.1 (StatSoft, Inc. 2005; www.statsoft.com).

\section{Results}

Spring warming effects on nutrient availability and total seston

The trends in total seston, soluble reactive phosphorus (SRP) and silicate during the course of the experiment are plotted in Fig. 2. As indicated by rANOVA, both SRP and total seston showed a significant response in time (Table 2). In all treatments, initially sharp ups and downs in concentrations of SRP could be observed (Fig. 2a). After day 10, SRP concentrations decreased more gradually, and from day 18 onwards SRP remained close to limiting levels $\left(<5 \mu \mathrm{g} \mathrm{SRP} \mathrm{l}^{-1}\right)$ for the remainder of the experimental period. Silicate levels (initial concentration $\left.=1666 \mu \mathrm{g} \mathrm{l}^{-1}\right) \quad$ reached limiting levels $\left(<500 \mu \mathrm{g} \mathrm{l}^{-1}\right)$ around day 10 (Fig. 2b). Total seston mass reached its maximum values around day 12 , after which it decreased to low levels $\left(<5 \mathrm{mg}\right.$ dry weight $\left.\mathrm{l}^{-1}\right)$ until day 45 of the experiment (Fig. 2a). Thereafter, a slow increase in total seston was observed. The time course of total seston differed significantly in response to the different climate scenarios (Table 2, interaction Climate $\times$ Time). 

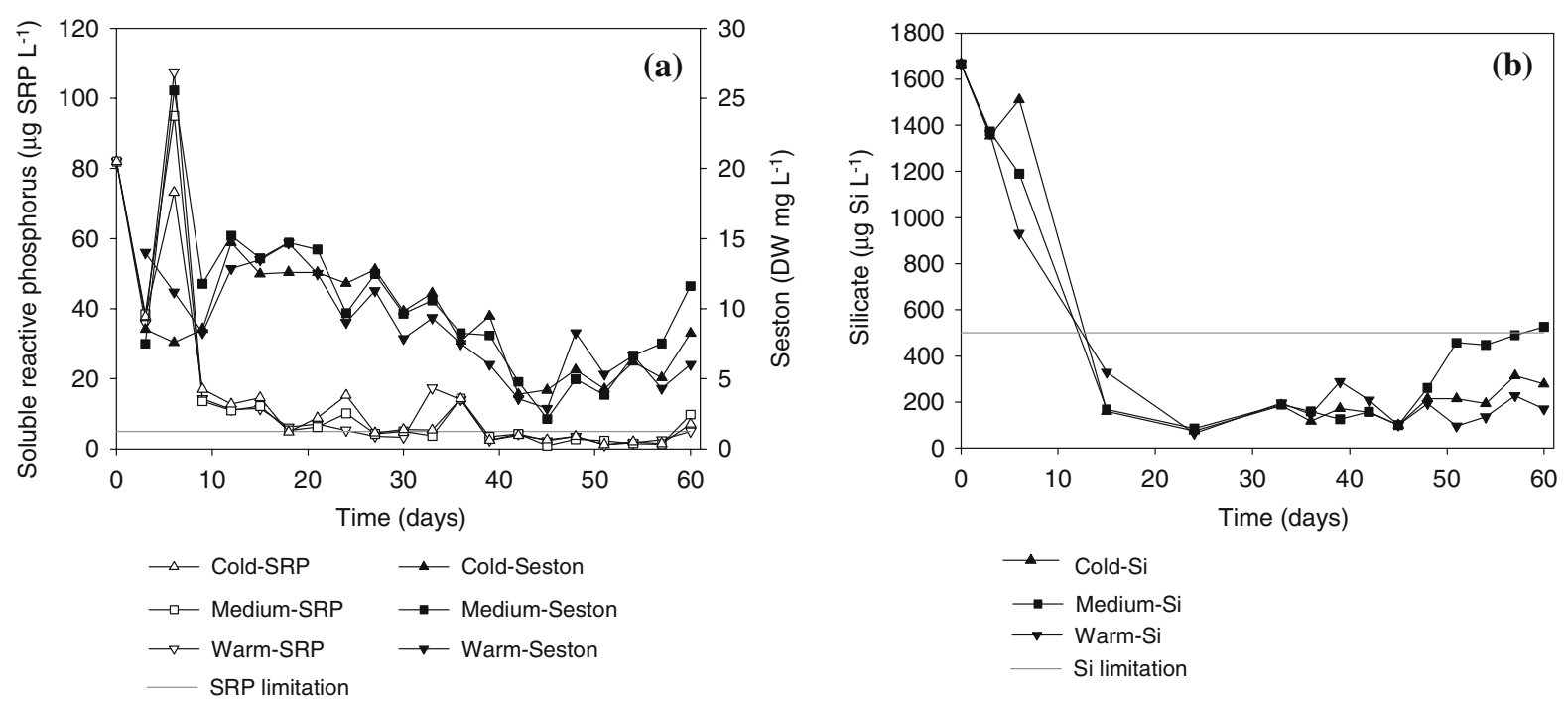

Fig. 2 Time course of the concentration of (a) soluble reactive phosphorus (open symbols) and total seston (closed symbols), and (b) silicate observed in the three climate scenarios simulated by the experiments

Table 2 Results of rANOVA testing the effect of the different climate warming scenarios (Climate) on the concentration of soluble reactive phosphorus (SRP) and dry weight of total seston during the course of the experiment (Time)

\begin{tabular}{|c|c|c|c|c|c|c|}
\hline \multirow[t]{2}{*}{ Effect } & \multicolumn{3}{|c|}{ SRP } & \multicolumn{3}{|c|}{ Total seston dry weight } \\
\hline & df & SS & $P$ & df & SS & $P$ \\
\hline Climate & 2 & 0.742 & n.s. & 2 & 115.12 & n.s. \\
\hline Time & 19 & 592.43 & $* *$ & 19 & 2581.29 & $* *$ \\
\hline Time $\times$ Climate & 38 & 31.64 & n.s. & 38 & 807.27 & $*$ \\
\hline
\end{tabular}

$* P<0.05, * * P<0.01$, n.s. $=$ not significant

Phytoplankton community response to spring warming

In all treatments, similar shifts in the relative abundances of cyanobacteria, green algae and diatoms were observed (Fig. 3). Diatoms were initially by far the most dominant phytoplankters; their rapid decline was followed by peaks of green algae and cyanobacteria at day 20 and day 30 , respectively. The green algae were more abundant than the cyanobacteria. The results of rANOVA underlined this significant response in time of the different algal functional groups (Table 3, mean effect Time). The time courses of all three algal functional groups (i.e. diatoms, cyanobacteria and green algae) differed significantly in response to the different climate scenarios (Table 3, interaction Climate $\times$ Time).
Model results

The model predictions showed a good fit with the experimental data of the algal groups (Fig. 4, $\left.R^{2}=0.875\right)$. The model captures the observed succession of an initial dominance of diatoms followed by a peak of green algae and cyanobacteria, although the modelled peaks of green algae and cyanobacteria shortly precede those observed in the experiment. The model predictions for the limiting nutrient showed a reasonably good fit with the experimental data on SRP concentrations (Fig. 4, $R^{2}=0.684$ ). We also examined slightly more complex models, to see whether the fit could be further improved. Inclusion of an extra loss term for the green algae and cyanobacteria resulted in $R^{2}=0.878$. Inclusion of a separate limiting nutrient for the green algae and a 

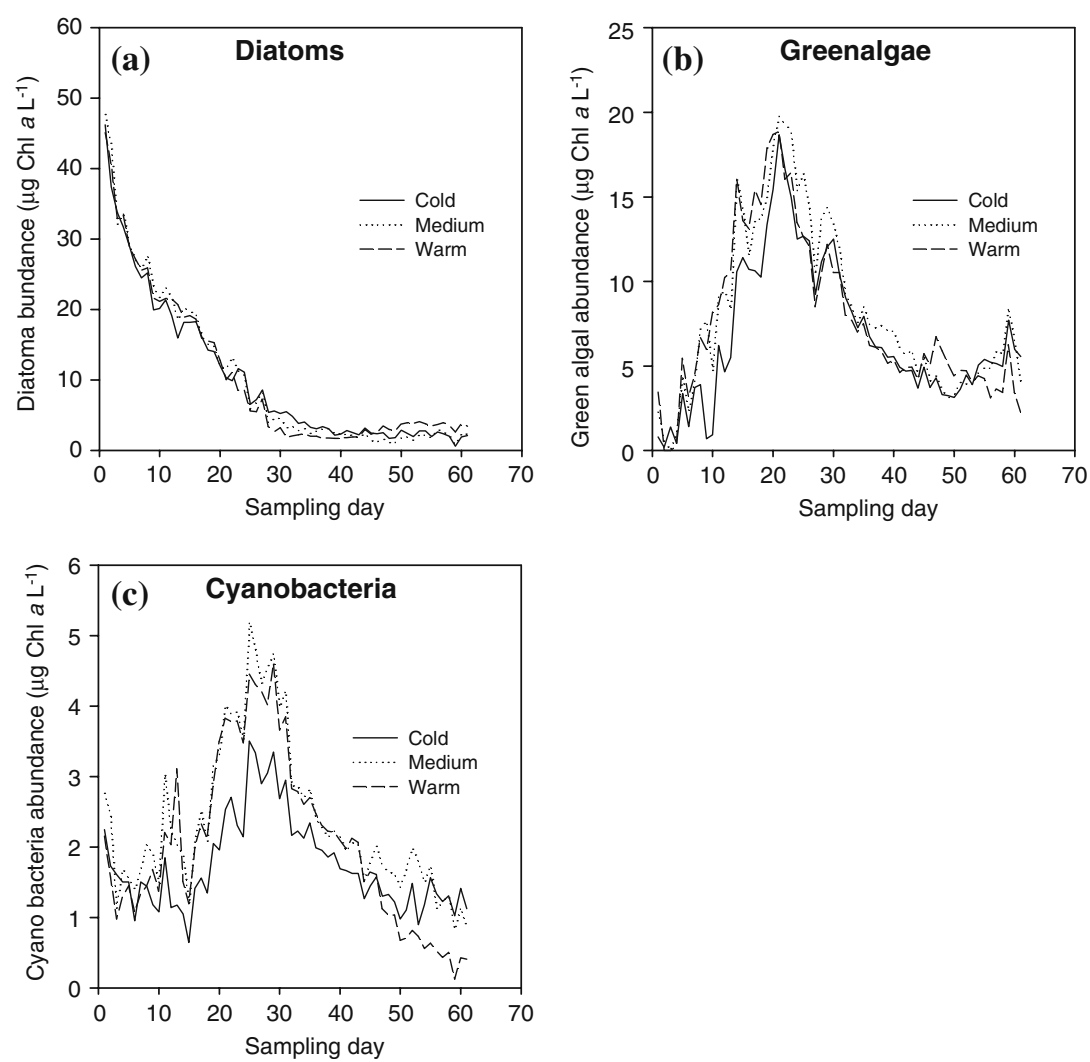

Fig. 3 Population dynamics (expressed as $\mu \mathrm{g} \mathrm{Chl} a \mathrm{l}^{-1}$ ) of (a) diatoms, (b) green algae, and (c) cyanobacteria observed in the three climate scenarios simulated by the

separate limiting nutrients for the cyanobacteria resulted in $R^{2}=0.886$. Inclusion of recycling of nutrients stored in the dead diatoms into the nutrient pool resulted in $R^{2}=0.868$. Because of the marginal improvement or even slight reduction of the fits for the more complex models, we proceeded our analysis with the original model.

Figure 5 displays the model estimates of the growth rate of cyanobacteria $\left(r_{\mathrm{C}}\right)$, the mortality rate of diatoms $\left(d_{\mathrm{D}}\right)$, and the growth rate of green

experiments. Cold $=$ cold spring scenario, Medium $=$ average spring scenario, Warm = warm spring scenario. Values are daily averages of climate treatments $(n=4)$

algae $\left(r_{\mathrm{G}}\right)$ for each of the three spring warming scenarios. The population dynamics predicted by the model (not shown, except for Fig. 4) revealed that especially the cyanobacteria reached higher abundances under the warm and medium climate scenarios ( $\max$ abundance 4.18 and $4.37 \mu \mathrm{g}$ Chl $a \mathrm{l}^{-1}$, respectively) than under the cold climate scenario (max abundance $3.34 \mu \mathrm{g} \mathrm{Chl} a \mathrm{l}^{-1}$ ). As indicated by ANOVA, the growth rate of cyanobacteria was significantly lower in the cold

Table 3 Results of rANOVA testing the effect of the different climate warming scenarios (Climate) on the abundance ( $\mu \mathrm{g} \mathrm{Chl} a \mathrm{l}^{-1}$ ) of cyanobacteria, diatoms and green algae during the course of the experiment (Time)

\begin{tabular}{|c|c|c|c|c|c|c|c|c|c|}
\hline \multirow[t]{2}{*}{ Effect } & \multicolumn{3}{|c|}{ Cyanobacteria } & \multicolumn{3}{|c|}{ Diatoms } & \multicolumn{3}{|c|}{ Green algae } \\
\hline & df & SS & $P$ & df & $S S$ & $P$ & df & SS & $P$ \\
\hline Climate & 2 & 37.07 & n.s. & 2 & 249.25 & n.s. & 2 & 507.24 & n.s. \\
\hline Time & 60 & 289.99 & $* *$ & 60 & 43356.55 & $* *$ & 60 & 6431.63 & $* *$ \\
\hline Time $\times$ Climate & 120 & 77.15 & $* *$ & 120 & 511.59 & $* *$ & 120 & 874.75 & $* *$ \\
\hline
\end{tabular}

$* P<0.05, * * P<0.01$, n.s. $=$ not significant 


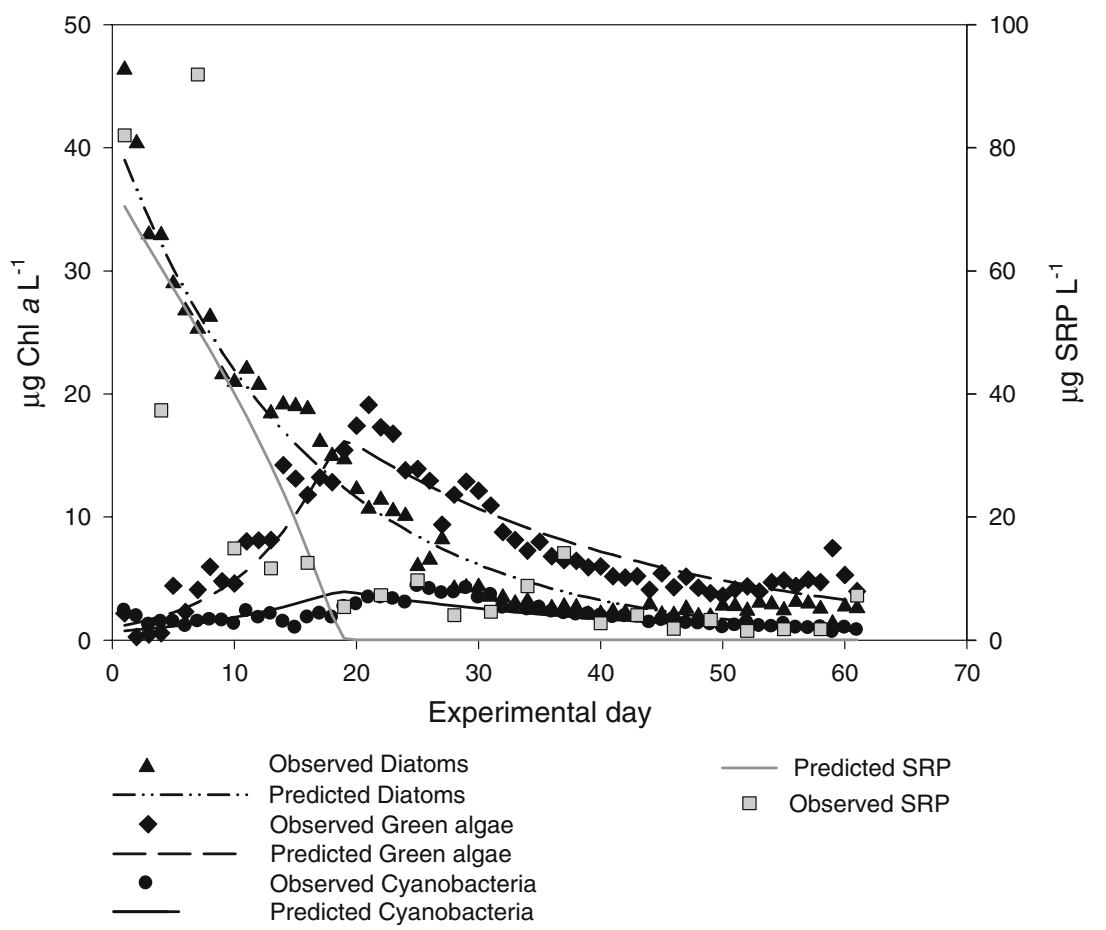

Fig. 4 Time course of diatoms, green algae, cyanobacteria and soluble reactive phosphorus observed in the experiments (symbols) and predicted by the mechanistic model (lines). The goodness of fit of the algal component of the

spring scenario than in the medium and warm spring scenarios (Fig. 5, $P<0.05$, Tukey HSD test). Although the growth rate of green algae also appeared lower in the cold spring scenario than in the medium and warm spring scenario, for green algae this effect was not significant (Fig. 5, $P=0.10)$. The mortality rate of the diatoms did not differ significantly between climate treatments (Fig. 5, $P=0.95$ ). Given the absence of significant differences in SRP concentrations between the different climate treatments (Table 3), we did not proceed with testing the model estimates of the nutrient content of the algae.

\section{Discussion}

The phytoplankton community in our cultures showed a significant response to the different spring warming scenarios. As tested by rANOVA, time courses of seston biomass were different between the different spring warming scenarios. This was mirrored by the response of model is indicated by $R^{2}=0.875$. The goodness of fit of the nutrient component of the model is indicated by $R^{2}=0.684$

the algal functional groups. The concentration of SRP did not differ significantly between different climate scenarios, suggesting that the responses of

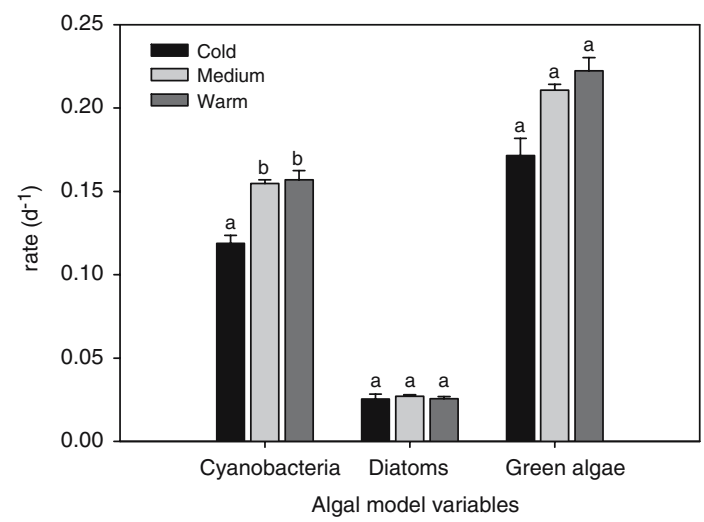

Fig. 5 Effects of the three climate scenarios on the growth rate of cyanobacteria $\left(r_{\mathrm{C}}\right)$, the mortality rate of diatoms $\left(d_{\mathrm{D}}\right)$, and the growth rate of green algae $\left(r_{\mathrm{G}}\right)$. Cold $=$ cold spring scenario, Medium $=$ average spring scenario, Warm = warm spring scenario. Bars show means with standard error. The different letters above bars represent significant differences as indicated by Tukey HSD 
the phytoplankton community to the climate scenarios were not driven by changes in nutrient availability. Our model results suggest that cyanobacteria show a stronger response to the different climate scenarios than green algae and diatoms. Other laboratory studies confirm the stronger response of cyanobacteria to rising temperatures (Reynolds, 1989; Coles \& Jones, 2000), which can result in a higher algal biomass. The differences in temperature sensitivity among cyanobacteria, green algae and diatoms, however, did not appear to affect the successional pattern of these groups in our experiments. In all climate scenarios, the initial dominance of diatoms was followed by successive peaks of green algae and cyanobacteria. In line with our results, Adrian et al. (1999) showed that the successional sequence of phytoplankton groups during spring was in general not affected by climate change.

Increases in the relative contribution of cyanobacteria with rising temperature have been observed in lakes across Europe (Adrian et al., 1995, 1999; Weyhenmeyer, 2001; Van de Bund et al., 2004). High abundances of cyanobacteria in freshwater systems can potentially disrupt trophic relationships, because of their low quality as a food source for invertebrate grazers (DeMott et al., 2001). Moreover, several cyanobacterial species can produce toxins, providing a serious threat for water quality, other aquatic organisms and human health (Carmichael, 2001; Huisman et al., 2005). Results of warming studies in outdoor mesocosms, however, point at the importance of species-specific responses to climate warming (Moss et al., 2003; Strecker et al., 2004). Individual species within major phytoplankton groups may respond very differently to changes in temperature. Furthermore, the effect of rising temperatures on species performances will depend not only on their temperature tolerance, but also on other species-specific characteristics such as nutrient requirements, buoyancy and light requirements (Reynolds et al., 2002).

Both experimental and model data reveal that nutrient limitation played an important role in the observed algal succession. Diatoms declined from the start of the experiment. The low availability of silicate measured in the culture medium, in combination with the relatively high sinking rates of diatoms (Reynolds et al., 1982; Reynolds \& Wiseman, 1982) offer a possible explanation for the strong decline of the diatom population. Moreover, silicate depletion is known to increase the sinking rates of diatom species (Bienfang et al., 1982). With the collapse of diatoms, green algae and cyanobacteria strongly increased, reaching peak abundances after 20 days and 30 days, respectively. Both the green algae and cyanobacteria started to decrease once SRP had reached (near) limiting levels. The depletion of SRP in our experiments matches the seasonal depletion of SRP observed in many mesotrophic lakes (Sommer et al., 1986). The good fit of the predicted limiting nutrient with the observed SRP concentrations provides further support that SRP is limiting the green algae and cyanobacteria in our experiments. As recycling of nutrients stored in dead diatoms back into the nutrient pool did not increase the fit of the model, we suggest that phosphorus stored in dead phytoplankton does not become available for cyanobacteria and green algae within the time span of the experiments.

In line with our initial hypothesis, our results highlight potential changes in plankton communities if the current trends in climate change continue (Straile \& Geller, 1998; Gerten \& Adrian, 2000; Kohler et al., 2005). In accordance with earlier findings from time series analysis (Gerten \& Adrian, 2000; Weyhenmeyer, 2001; Weyhenmeyer et al., 2002), we found that, qualitatively, the spring sequence of succession from diatoms to green algae to cyanobacteria is not affected by different climate scenarios. Quantitatively, however, different algal groups show a different response. In particular, cyanobacteria respond more strongly to rising temperatures than green algae and diatoms, resulting in higher growth rates and peak abundances of cyanobacteria in a warming climate.

Acknowledgments We thank K. Siewertsen, N. Helmsing, M. Kagami and I. van der Stap for assistance with sampling. K. Siewertsen carried out the nutrient analyses. Hennie Uittenhout designed and constructed the sampling devices. We thank J. Vijverberg, S. Hülsmann, and R. Gulati, and the anonymous reviewers for their helpful comments. This study was funded by the Biodiversity program of the Earth and Life Sciences Foundation 
(ALW), which is subsidized by the Netherlands Organization for Scientific Research (NWO grant $852.00 .010 / 852.00 .012)$. This is publication 3950 of the Netherlands Institute of Ecology (NIOO-KNAW).

\section{References}

Adrian, R., R. Deneke, U. Mischke, R. Stellmacher, \& P. Lederer, 1995. Long-term study of the Heiligensee (1975-1992) -Evidence for effects of climatic-change on the dynamics of eutrophied lake ecosystems. Archiv für Hydrobiologie 133: 315-337.

Adrian, R., N. Walz, T. Hintze, S. Hoeg, \& R. Rusche, 1999. Effects of ice duration on plankton succession during spring in a shallow polymictic lake. Freshwater Biology 41: 621-632.

Beisner, B. E., E. McCauley, \& F. J. Wrona, 1996. Temperature-mediated dynamics of planktonic food chains: the effect of an invertebrate carnivore. Freshwater Biology 35: 219-232.

Beisner, B. E., E. McCauley, \& F. J. Wrona, 1997. The influence of temperature and food chain length on plankton predator-prey dynamics. Canadian Journal of Fisheries and Aquatic Sciences 54: 586-595.

Bienfang, P. K., P. J. Harrison, \& L. M. Quarmby, 1982. Sinking rate response to depletion of nitrate, phosphate and silicate in 4 marine diatoms. Marine Biology 67: 295-302.

Carmichael, W. W., 2001. Health effects of toxin-producing cyanobacteria: "The CyanoHABs". Human and Ecological Risk Assessment 7: 1393-1407.

Christoffersen, K., N. Andersen, M. Sondergaard, L. Liboriussen, \& E. Jeppesen, 2006. Implications of climate-enforced temperature increases on freshwater pico- and nanoplankton populations studied in artificial ponds during 16 months. Hydrobiologia 560: 259266.

Coles, J. F. \& R. C. Jones, 2000. Effect of temperature on photosynthesis-light response and growth of four phytoplankton species isolated from a tidal freshwater river. Journal of Phycology 36: 7-16.

De Nie, H. W., H. J. Bromley, \& J. Vijverberg, 1980. Distribution patterns in Tjeukemeer, The Netherlands. Journal of Plankton Research 2: 316-334.

DeMott, W. R., R. D. Gulati, \& E. Van Donk, 2001. Daphnia food limitation in three hypereutrophic Dutch lakes: Evidence for exclusion of large-bodied species by interfering filaments of cyanobacteria. Limnology and Oceanography 46: 2054-2060.

Elliott, J. A., I. D. Jones, \& S. J. Thackeray, 2006. Testing the sensitivity of phytoplankton communities to changes in water temperature and nutrient load, in a temperate lake. Hydrobiologia 559: 401-411.

Gerten, D. \& R. Adrian, 2000. Climate-driven changes in spring plankton dynamics and the sensitivity of shallow polymictic lakes to the North Atlantic Oscillation. Limnology and Oceanography 45: 1058-1066.
Golterman, H. L., R. S. Clymo, \& M. A. M. Ohnstad, 1978. Methods of Physical and Chemical Analysis of Fresh Waters. Blackwell, Oxford, United Kingdom.

Harris, G. P. \& G. Baxter, 1996. Interannual variability in phytoplankton biomass and species composition in a subtropical reservoir. Freshwater Biology 35: $545-560$.

Houghton, J. D., Y. Ding, D. J. Griggs, M. Noguer, P. J. Van der Linden, \& D. Xiaosu, 2001. Climate Change 2001: The Scientific Basis Contribution Of Working Group I to the Third Assessment Report of the Intergovernmental Panel on Climate Change (IPCC). Cambridge University Press, Cambridge, U.K.

Huisman, J., H. C. P. Matthijs, \& P. M. Visser, 2005. Harmful Cyanobacteria. Springer, Berlin, Germany.

Huisman, J., J. Sharples, J. M. Stroom, P. M. Visser, W. E. A. Kardinaal, J. M. H. Verspagen, \& B. Sommeijer, 2004. Changes in turbulent mixing shift competition for light between phytoplankton species. Ecology 85: 2960-2970.

Kohler, J., S. Hilt, R. Adrian, A. Nicklisch, H. P. Kozerski, \& N. Walz, 2005. Long-term response of a shallow, moderately flushed lake to reduced external phosphorus and nitrogen loading. Freshwater Biology 50: 1639-1650.

Kors, A. G., F. A. M. Claessen, J. W. Wesseling, \& G. P. Können, 2000. Scenario's externe krachten voor WB21. Commissie Waterbeheer 21e eeuw, RIZA, WL/Delft Hydraulics en KNMI rapport.

Mckee, D., D. Atkinson, S. E. Collings, J. W. Eaton, A. B. Gill, I. Harvey, K. Hatton, T. Heyes, D. Wilson, \& B. Moss, 2003. Response of freshwater microcosm communities to nutrients, fish, and elevated temperature during winter and summer. Limnology and Oceanography 48: 702-722.

Mooij, W. M., 1996. Variation in abundance and survival of fish larvae in shallow eutrophic Lake Tjeukemeer. Environmental Biology of Fishes 46: 265-279.

Mooij, W. M., S. Hülsmann, L. N. De Senerpont Domis, B. A. Nolet, P. L. E. Bodelier, P. C. M. Boers, L. M. Dionisio Pires, H. J. Gons, B. W. Ibelings, R. Noordhuis, R. Portielje, K. Wolfstein, \& E. H. R. R. Lammens, 2005. The impact of climatic change on lakes in the Netherlands: a review. Aquatic Ecology 39: 381-400.

Mooij, W. M., \& O. F. R. Van Tongeren, 1990. Growth of $0+$ roach (Rutilus rutilus) in relation to temperature and size in a shallow eutrophic lake - comparison of field and laboratory observations. Canadian Journal of Fisheries and Aquatic Sciences 47: 960-967.

Moss, B., D. Mckee, D. Atkinson, S. E. Collings, J. W. Eaton, A. B. Gill, I. Harvey, K. Hatton, T. Heyes, \& D. Wilson, 2003. How important is climate? Effects of warming, nutrient addition and fish on phytoplankton in shallow lake microcosms. Journal of Applied Ecology 40: 782-792.

Müller-Navarra, D. C., S. Guss, \& H. Von Storch, 1997. Interannual variability of seasonal succession events in a temperate lake and its relation to temperature variability. Global Change Biology 3: 429-438. 
Murphy, J., \& J. P. Riley, 1962. A modified single solution method for determination of phosphate in natural waters. Analytica Chimica Acta 27: 31-36.

Parmesan, C., \& G. Yohe, 2003. A globally coherent fingerprint of climate change impacts across natural systems. Nature 421: 37-42.

Reynolds, C. S., 1989. Physical determinants of phytoplankton succession. In Sommer, U. (ed), Plankton Ecology. Succession in Plankton Communities. Springer-Verlag: 9-56.

Reynolds, C. S., 1997. Vegetation Processes in the Pelagic: a Model for Ecosystem Theory. Ecology Institute, Oldendorf/Luhe.

Reynolds, C. S., V. Huszar, C. Kruk, L. Naselli-Flores, \& S. Melo, 2002. Towards a functional classification of the freshwater phytoplankton. Journal of Plankton Research 24: 417-428.

Reynolds, C. S., J. M. Thompson, A. J. D. Ferguson, \& S. W. Wiseman, 1982. Loss processes in the population dynamics of phytoplankton maintained in closed systems. Journal of Plankton Research 4: 561-600.

Reynolds, C. S. \& S. W. Wiseman, 1982. Sinking losses of phytoplankton in closed limnetic systems. Journal of Plankton Research 4: 489-522.

Sommer, U., 1985. Comparison between steady-state and non-steady state competition: experiments with natural phytoplankton. Limnology and Oceanography 30: 335-346.

Sommer, U., Z. M. Gliwicz, W. Lampert, \& A. Duncan, 1986. The PEG-Model of seasonal succession of planktonic events in fresh waters. Archiv für Hydrobiologie 106: 433-471.

Straile, D., \& W. Geller, 1998. The response of Daphnia to changes in trophic status and weather patterns: a case study from Lake Constance. ICES Journal of Marine Science 55: 775-782.

Strecker, A. L., T. P. Cobb, \& R. D. Vinebrooke, 2004. Effects of experimental greenhouse warming on phytoplankton and zooplankton communities in fishless alpine ponds. Limnology and Oceanography 49: 1182-1190.

Van de Bund, W. J., S. Romo, M. J. Villena, M. Valentin, E. Van Donk, E. Vicente, K. Vakkilainen, M. Svensson, D. Stephen, A. Stahl-Delbanco, J. Rueda, B. Moss, M. R. Miracle, T. Kairesalo, L. A. Hansson, J. Hietala, M. Gyllstrom, J. Goma, P. Garcia, M. Fernandez-Alaez, C. Fernandez-Alaez, C. Ferriol, S.
E. Collings, E. Becares, D. M. Balayla, \& T. Alfonso, 2004. Responses of phytoplankton to fish predation and nutrient loading in shallow lakes: a pan-European mesocosm experiment. Freshwater Biology 49: 16081618.

Van Oldenborgh, G. J., \& A. Van Ulden, 2003. On the relationship between global warming, local warming in the Netherlands and changes in circulation in the 20th century. International Journal of Climatology 23: 1711-1724.

Van Vliet, A. J. H., A. Overeem, R. S. De Groot, A. F. G. Jacobs, \& F. T. M. Spieksma, 2002. The influence of temperature and climate change on the timing of pollen release in the Netherlands. International Journal of Climatology 22: 1757-1767.

Verschoor, A. M., J. Takken, B. Massieux, \& J. Vijverberg, 2003. The Limnotrons: a facility for experimental community and food web research. Hydrobiologia 491: 257-377.

Walther, G. R., E. Post, P. Convey, A. Menzel, C. Parmesan, T. J. C. Beebee, J. M. Fromentin, O. Hoegh-Guldberg, \& F. Bairlein, 2002. Ecological responses to recent climate change. Nature 416: 389 395.

Walz, H., 1999. Phytoplankton Analyzer PHYTO-PAM: System components and principles of operation. Heinz Walz, Effeltrich, Germany.

Weyhenmeyer, G. A., R. Adrian, U. Gaedke, D. M. Livingstone, \& S. C. Maberly, 2002. Response of phytoplankton in European lakes to a change in the North Atlantic Oscillation. Verhandlungen Internationale Vereinigung für Theoretische und Angewandte Limnologie 20: 1436-1439.

Weyhenmeyer, G. A., 2001. Warmer winters: Are planktonic algal populations in Sweden's largest lakes affected? Ambio 30: 565-571.

Weyhenmeyer, G. A., T. Blenckner, \& K. Pettersson, 1999. Changes of the plankton spring outburst related to the North Atlantic Oscillation. Limnology and Oceanography 44: 1788-1792.

Winder, M. \& D. E. Schindler, 2004a. Climate change uncouples trophic interactions in an aquatic ecosystem. Ecology 85: 2100-2106.

Winder, M. \& D. E. Schindler, 2004b. Climatic effects on the phenology of lake processes. Global Change Biology 10: 1844-1856. 